\title{
Projections of declining surface-water availability for the southwestern United States
}

\author{
Richard Seager ${ }^{1 \star}$, Mingfang Ting ${ }^{1}$, Cuihua Li ${ }^{1}$, Naomi Naik ${ }^{1}$, Ben Cook $^{2}$, Jennifer Nakamura ${ }^{1}$ \\ and Haibo Liu' ${ }^{1}$
}

\begin{abstract}
Global warming driven by rising greenhouse-gas concentrations is expected to cause wet regions of the tropics and mid to high latitudes to get wetter and subtropical dry regions to get drier and expand polewards ${ }^{1-4}$. Over southwest North America, models project a steady drop in precipitation minus evapotranspiration, $P-E$, the net flux of water at the land surface $^{5-7}$, leading to, for example, a decline in Colorado River flow $^{8-11}$. This would cause widespread and important social and ecological consequences ${ }^{12-14}$. Here, using new simulations from the Coupled Model Intercomparison Project Five, to be assessed in Intergovernmental Panel on Climate Change Assessment Report Five, we extend previous work by examining changes in $P, E$, runoff and soil moisture by season and for three different water resource regions. Focusing on the near future, 2021-2040, the new simulations project declines in surface-water availability across the southwest that translate into reduced soil moisture and runoff in California and Nevada, the Colorado River headwaters and Texas.
\end{abstract}

The global climate models used in this study include all simulations for all models that were continuous from 1950 to 2040 and that provided all of the data required. Historical simulations to December 2005 and future projections to 2040 using the Representative Concentration Pathway (RCP) 85 scenario whereby anthropogenic radiative forcing equals $8.5 \mathrm{~W} \mathrm{~m}^{-2}$ by 2100 (refs. 15 , 16) were analysed (see Methods). The RCP85 scenario involves stronger anthropogenic radiative forcing than the Special Report on Emissions Scenario A1B for Coupled Model Intercomparison Project (CMIP) 3/Intergovernmental Panel on Climate Change Assessment Report Four analysed in ref. 5, and was chosen to reflect the present lack of any international action to limit $\mathrm{CO}_{2}$ emissions. The models are being evaluated as part of CMIP5 and have been shown to model important aspects of North American hydroclimate with fidelity but with biases, for example, to excess $P$ in the interior of western North America (see Supplementary Information).

In both the models and the observations, California gets almost all of its annual $P$ in the winter, whereas inland regions such as the Colorado headwaters and Texas have a more even distribution of $P$ throughout the year (see Supplementary Information). However, in all cases, winter $P$ has a disproportionate importance from the water-resource perspective because $E$ is lowest during winter and $P$ is effective at increasing soil moisture, streamflows and reservoir storage, often with a delay until snowmelt ${ }^{8}$. Summer rains are however very important for dry farming, rangelands and ecosystems and for influencing fire risk ${ }^{17}$. Figure 1 shows the changes in the multimodel ensemble mean $P$ and $P-E$ for North America for 2021-2040 minus 1951-2000 by season. Winter (January-March, JFM) $P$ declines across Mexico, southern California, southern and central Arizona and New Mexico and almost all of Texas. To the north, in central and northern California, Nevada, Utah and Colorado the models project increased winter $P$. In spring (April-June, AMJ) the region of reduced $P$ extends to include all of California and most of Utah, Nevada and Oregon.

Southwest North America is also projected to warm in the coming decades as a consequence of rising greenhouse-gas concentrations (see Supplementary Information) and the increased evaporative demand can drive higher $E$ (ref. 18), which can lead to an increase in $P$ through moisture recycling or atmospheric export of evaporated moisture ${ }^{19,20}$. Hence, a better measure of future water availability is the change in $P-E$, the net flux of water substance at the land surface (Fig. 1). The region of projected winter drying includes all of Mexico, Texas, New Mexico, Arizona and most of Utah and Nevada. Winter $P-E$ increases in northern California but by less than $P$ increases. In spring, northern Mexico, Texas and the southern parts of Arizona and New Mexico all have increased mean $P-E$, although $P$ decreases in much of this same area. The strongest (order $0.3 \mathrm{~mm} \mathrm{~d}^{-1}$ ) reductions of $P-E$ are in California, Nevada, Utah and Colorado. In summer, $P$ is projected to decline across all of the western Pacific states, Idaho and Nevada and also in Oklahoma and Kansas but to increase in the Four Corners region and at the intersection of northern Mexico, New Mexico and Texas. Summer $P-E$ becomes more positive in southern California, southern Nevada, Arizona, western New Mexico and much of Texas and becomes more negative in regions to the north. In regions where spring and summer $P-E$ becomes more positive even as $P$ decreases it is because $E$ decreases consistent with less soil moisture due to a drop in previous winter season $P$.

To examine how consistently models project drying in the southwest US, and how this varies with time, in Fig. 2 we show the results for all of the simulations with all of the models plotted as the change in $P-E$ for two-decade periods in the present century (2001-2020, 2021-2040 and so on) relative to 1951-2000 averaged over three quite different water resource regions. These are California and Nevada (here represented by $32^{\circ}-42^{\circ} \mathrm{N}, 125^{\circ}-113^{\circ} \mathrm{W}$, land areas alone). California obtains most of its water from the Sierra Nevada Mountain Range, on which it largely falls as snow in winter ${ }^{21}$. The second region is the Colorado River headwaters $\left(37^{\circ}-42^{\circ} \mathrm{N}\right.$, $112^{\circ}-106^{\circ} \mathrm{W}$ ), which receive substantial winter snowfall as well as summer rainfall, and feed the Colorado River, which provides water to 7 states and Mexico ${ }^{8,12,22}$. The third region is Texas $\left(26^{\circ}-36^{\circ} \mathrm{N}\right.$, $103^{\circ}-93^{\circ} \mathrm{W}$, land areas alone), which uses water from rivers and groundwater within its own borders ${ }^{23}$. For each model, the changes for individual runs are plotted as black dots and the ensemble mean as a red dot. As such the influence of natural variability on the two-decade means is represented in the scatter of the black dots 

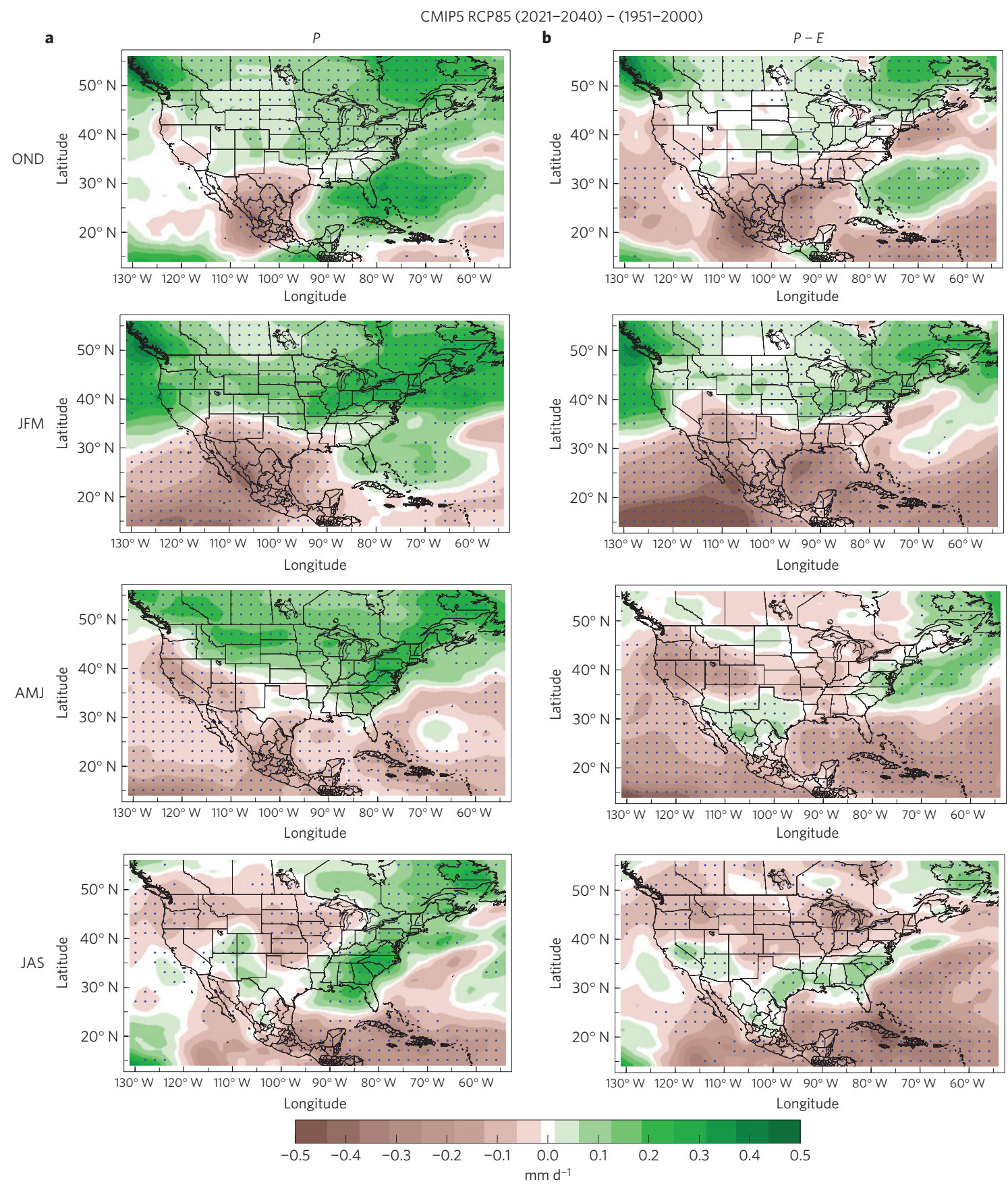

Figure 1 | The average across the 16 CMIP5 models of the change in $P$ and $P-E$ for 2021-2040 minus 1951-2000, using the RCP85 emissions scenario for the future and the simulations with historical forcing for the past. All simulations of each model that were continuous were used in the analysis with averaging across each model ensemble performed first before creating the multimodel ensemble. Dots indicate that three-quarters of the models and the all-model mean agree on the sign of the projected change. Results are shown for, from top to bottom, autumn (OND), winter (JFM), spring (AMJ) and summer (JAS) with seasons chosen so that autumn begins with the beginning of the hydrological year.

around the ensemble mean. Despite this inclusion of the full impact of model natural variability, it is clear that in the next two-decade period, and more so by the mid-century, most (it ranges between 59 and $78 \%$ ) of the simulations project a decrease in $P-E$ in each of the three regions. Drying intensifies as the century advances.

From the point of view of applications in water resources, agriculture, and land and ecosystem management, it is the impact of changes in $P-E$ on runoff and soil moisture that is important. In addition, as much of the region's water storage depends on inflows from winter $P$, whereas crops depend on soil moisture in the growing season, changes by season, as opposed to just the annual mean, are important. In Fig. 3 we therefore show the changes in $P, E$, soil moisture and runoff for the three regions for four seasons and the annual mean, and for 2021-2040 minus 1951-2000 in the form of box and whisker diagrams. In the JFM season, median (indicated by the horizontal line across the box) $P$ shows little change, and mean (shown by the asterisk) $P$ increases when averaged over California and Nevada, and both mean and median $P$ increase when averaged over the Colorado headwaters. However, in both regions mean and median $E$ increase (driven by warming). For California and Nevada all model runs have an increase in $E$ and for the Colorado headwaters more than $75 \%$ have an increase in $E$. The net effect is that in 

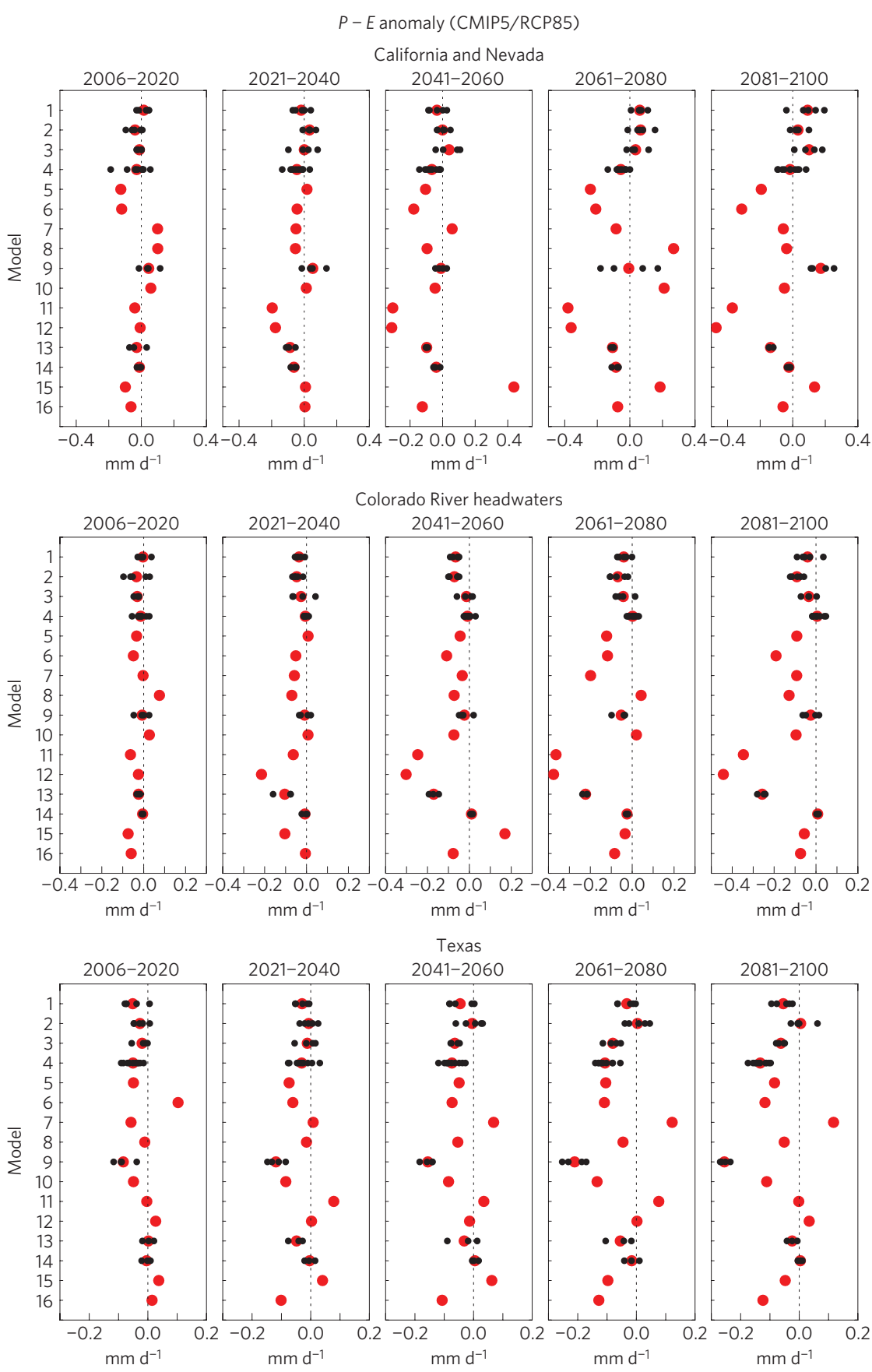

Figure 2 | The difference in P-E relative to 1951-2000 for two-decade periods of the present century for the California and Nevada region, the

Colorado River headwaters region and the Texas region. The vertical axis refers to the individual model numbers as in the Supplementary Table. Black dots show the change in $P-E$ for the five two-decade periods for the individual continuous runs with the model. The red dots show the ensemble mean change for each model. For models with single continuous runs only the red dot is plotted. The twenty-first-century projections use the RCP85 emissions scenario.

both areas $P-E$ in the JFM season changes little (see Supplementary Information) and neither does soil moisture. Changes in JFM runoff for California and Nevada are also scattered around no change but for the Colorado headwaters $75 \%$ of the model runs have an increase in JFM runoff with a mean increase of about $25 \%$, probably caused by more of $P$ falling as rain instead of snow and/or earlier snowmelt ${ }^{24}$. In contrast, in Texas during JFM, 75\% of model runs have a $P$ decrease, $E$ increases and $75 \%$ or more of model runs have notable declines in both soil moisture and runoff.

For California and Nevada, in the remaining seasons, most model runs have both a decrease in $P$ and an increase in $E$ (other than in JJA) that translates into the mean, median and most of the model runs having declines in both runoff and soil moisture. Of these, the most pronounced change is an about $20 \%$ decline in spring runoff that is driven by a drop in spring $P$.

In the Colorado headwaters mean $P$ actually increases in all seasons and the median does in all but AMJ. However, a clear model tendency for increased $E$ throughout the year translates into a tendency for a decline in soil moisture in spring, summer and autumn. Runoff declines in spring by about $25 \%$ in the mean, primarily because of a large increase in $E$ driven by warming (see Supplementary Information), but increases in autumn probably owing to more of the total $P$ falling as rain instead of snow (as in winter, for example ref. 25). 

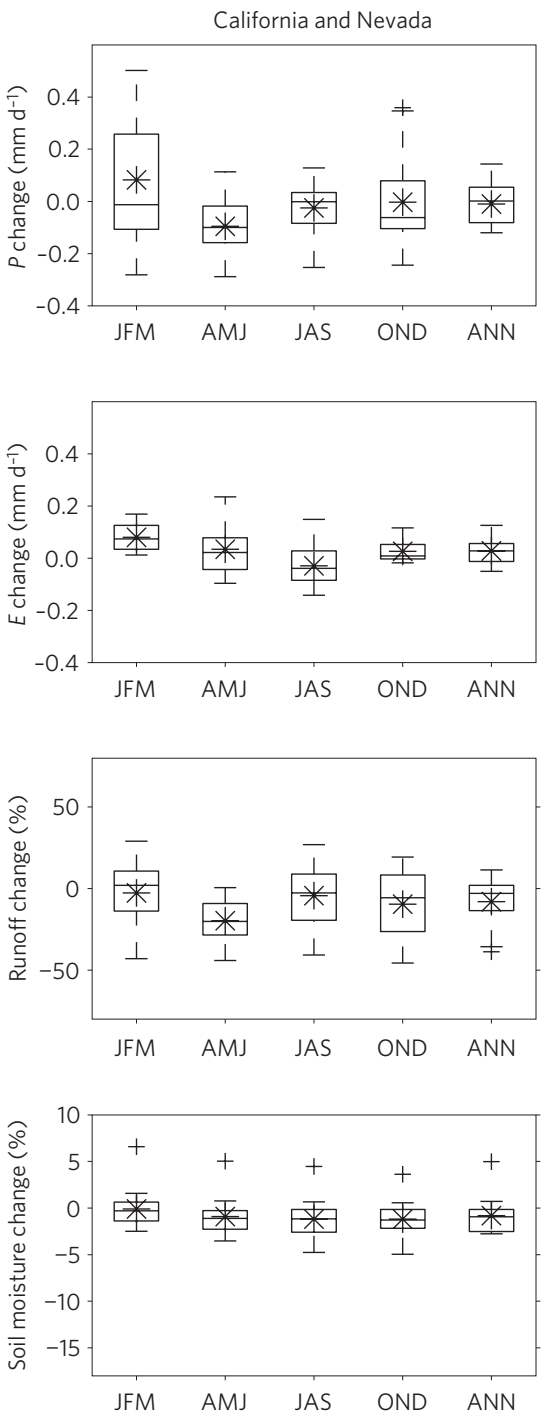

b
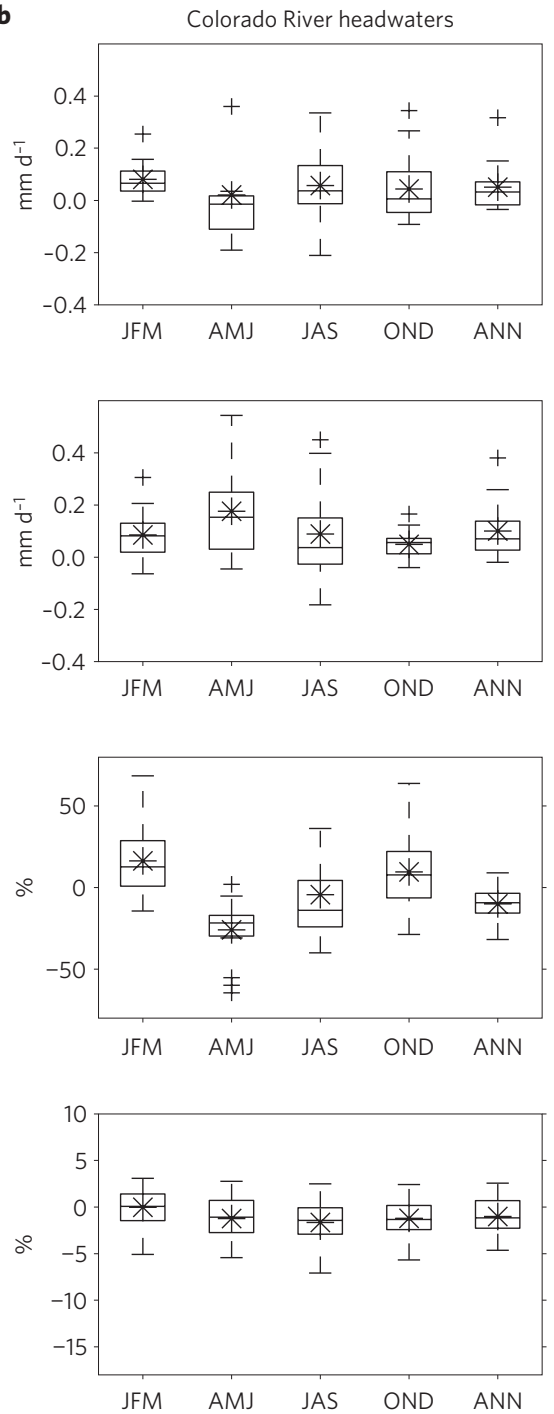

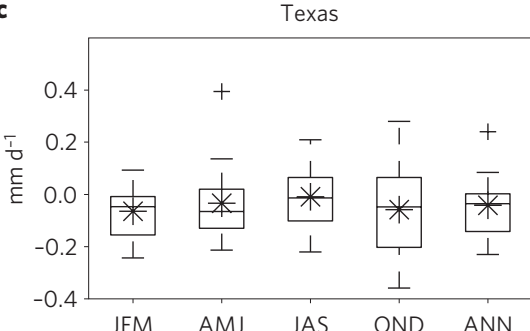

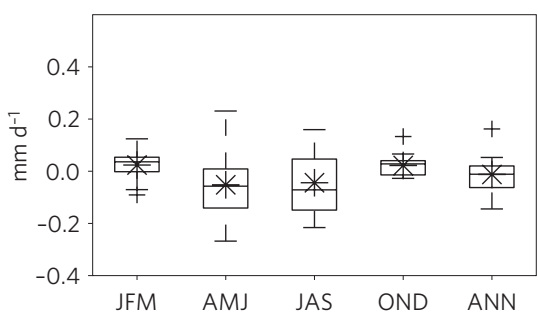
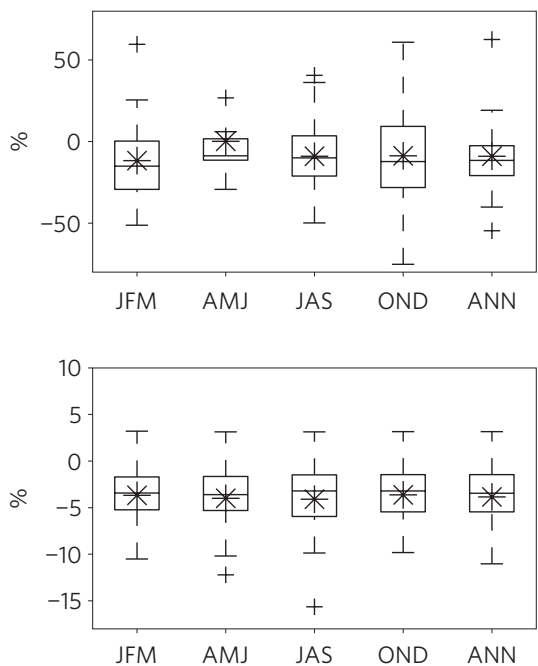

Figure 3 | Changes by season in P, E, runoff and soil moisture for 2021-2040 under the RCP85 emissions scenario minus $1951-2000$ using the 16 model CMIP5 ensemble. Differences are computed for each continuous model run first and then the distributions across the models are plotted as box and whisker diagrams. The 25th and 75th percentiles of the model distributions are shown by the edges of the boxes, the medians are plotted as the horizontal lines within the boxes and the whiskers mark the 5th and 95th percentiles. Asterisks indicate the mean. a-c, Results for the California and Nevada region

(a), the Colorado River headwaters region (b) and the Texas region (c).

In Texas, mean and median $P$ decline in all seasons except summer. Mean and median $E$ decrease in spring and summer but increase modestly in winter and autumn. Reduced $E$ in spring and summer follows on from reduced $P$ in the preceding autumn and winter. These changes translate into median drops in runoff of around $10 \%$ or more year round and consistent and robust drops in soil moisture but only by a few per cent.

In the annual average, the mean and median runoff decreases in all three regions by about $10 \%$, with greater model agreement (more than $75 \%$ of model runs) for the Colorado headwaters and Texas than for California and Nevada. Annual average mean and median soil moisture also decreases in all three regions with the largest and most certain drop in Texas but by less than $5 \%$.

The patterns and magnitudes of near-term changes in $P-E$ across North America reported here confirm earlier results ${ }^{5}$. As climate models have advanced since the previous analysis, including in their spatial resolution, this increases confidence in the projections of drying in the southwest. However, it should be noted that state-of-the-art global models still cannot fully represent the complex topography of western North America and its effect on regional climate (see Supplementary Information). The present work extends the earlier work by analysing the changes by season and the impacts on runoff and soil moisture in key regions. California and Nevada are heavily dependent on winter $P$, which is projected to increase in the northern parts of the region. Despite this, projected increases in winter and spring $E$ cause a projected decrease in runoff in spring and soil moisture throughout the year. In a quite different climatic environment, a projected decrease in Colorado headwaters runoff and soil moisture arises from a projected increase in $E$. Texas is more likely to experience a decrease in $P$ in most seasons that is sufficient to drive a decrease in $E$ in spring and summer and a likely year-round drop in runoff and soil moisture. The decreases in runoff reach $10 \%$ or more in the annual average and around $25 \%$ in spring for the Colorado headwaters, amounts that compare well with the warming-induced reductions calculated by ref. 26 . In all cases, the model ensemble includes some members that have increases in runoff and soil moisture in coming decades, emphasizing the fact that for 2021-2040 the amplitude of the anthropogenic drying is comparable to that of natural decadal 
variability. However, for soil moisture in Texas and runoff in the Colorado headwaters and Texas more than $75 \%$ of model simulations project a near-term decline.

For context, a reduction in Colorado River flow of $10 \%$ is comparable to the variability of decadal mean flows over the past century (for example, ref. 8 and Supplementary Information). Furthermore, a 1,200-year tree-ring reconstruction of Colorado River flow at Lee's Ferry ${ }^{27}$ has the very lowest value of 20 -year means (during the twelfth-century megadrought), about $15 \%$ lower than the long-term mean (see also ref. 28). Hence, anthropogenic climate change is projected to lead to a potential reduction of Colorado River flow comparable to the most severe, but temporary, long-term decreases in flow recorded. These projected declines in surface-water availability for the coming two decades are probably of sufficient amplitude to place additional stress on regional water resources given the pressure of meeting agricultural demands as well as those of a growing population while needing to preserve riparian ecosystems.

\section{Methods}

Model simulations were selected from the CMIP5 archive that were continuous from 1950 to 2040 between the historical simulations and the RCP85 projection. The RCP85 emissions scenario is comparable to the business-as-usual scenario within CMIP3 and represents a continuation of no mitigation and high emissions. In 2040, the $\mathrm{CO}_{2}$ concentration in RCP85 is $489 \mathrm{ppm}$. The $\mathrm{CO}_{2}$ concentration difference between this scenario and the RCP 45 scenario, which represents some mitigation, is almost zero in 2021 and $29 \mathrm{ppm}$ in 2040 and then diverges strongly in the later half of the twentieth century. Models were used if they contained data for $P, E$, surface air temperature, soil moisture and runoff. This led to exclusion of some models and simulations, leaving 16 models. For these 16 models, the data were then regridded to a common one-degree-latitude by one-degree-longitude grid. (Results were essentially the same when regridded to a coarser two-degree grid.) Using these 16 models we formed ensemble means for each model by averaging together all of the retained simulations conducted with that model. With this multimodel ensemble the mean, median and 25th and 75th percentiles of the spread across the multimodel ensemble were computed for the differences in $P, E, P-E$, surface air temperature, runoff and soil moisture. Details on the models used, their resolution and their simulations of the seasonal cycles of $P$ and runoff and natural decadal variability of $P-E$ in the southwest can be found in the Supplementary Information.

Received 17 July 2012; accepted 22 November 2012; published online 23 December 2012

\section{References}

1. Held, I. M. \& Soden, B. J. Robust responses of the hydrological cycle to global warming. J. Clim. 19, 5686-5699 (2006).

2. IPCC Climate Change 2007: The Physical Science Basis (eds Solomon, S. et al.) (Cambridge Univ. Press, 2007).

3. Chou, C., Neelin, J. D., Chen, C-A. \& Tu, J-Y. Evaluating the 'Rich-Get-Richer' mechanism in tropical precipitation change under global warming. J. Clim. 22, 1982-2005 (2009).

4. Seager, R., Naik, N. \& Vecchi, G. Thermodynamic and dynamic mechanisms for large scale changes in the hydrological cycle in response to global warming. J. Clim. 23, 4651-4668 (2010).

5. Seager, R. et al. Model projections of an imminent transition to a more arid climate in southwest North America. Science 316, 1181-1184 (2007).

6. Seager, R. \& Vecchi, G. Greenhouse warming and the 21 st century hydroclimate of southwestern North America. Proc. Natl Acad. Sci. USA 107, 21277-21282 (2010).

7. Cayan, D. R. et al. Future dryness in the southwest US and the hydrology of the early 21 st century drought. Proc. Natl Acad. Sci. USA 107, 21271-21276 (2010).

8. Christensen, N. \& Lettenmaier, D. P. A multimodel ensemble approach to assessment of climate change impacts on the hydrology and water resources of the Colorado River basin. Hydrol. Earth Syst. Sci. 3, 1-44 (2007).
9. Barnett, T. P. \& Pierce, D. W. Sustainable water deliveries form the Colorado River in a changing climate. Proc. Natl Acad. Sci. USA 106, 7334-7338 (2009).

10. Hoerling, M. P., Lettenmeier, D. P., Cayan, D. R. \& Udall, B. Reconciling projections of Colorado River streamflow. Southwest Hydrol. 8, 20-21 (2009).

11. Rajagopalan, B. et al. Water supply on the Colorado River: Can management mitigate? Water Resour. 45, W08201 (2009).

12. MacDonald, G. M. Water, climate change, and sustainability in the southwest. Proc. Natl Acad. Sci. USA 107, 21256-21262 (2010).

13. Adams, H. D. et al. Temperature sensitivity of drought-induced tree mortality portends increased regional die-off under global change-type drought. Proc. Natl Acad. Sci. USA 106, 7063-7066 (2010).

14. Williams, A. P. et al. Forest responses to increasing aridity and warmth in the southwestern United States. Proc. Natl Acad. Sci. USA 107, 21289-21294 (2010).

15. Taylor, K. E., Stouffer, R. J. \& Meehl, G. A. An overview of CMIP5 and the experiment design. Bull. Am. Meterorol. Soc. 93, 485-498 (2012).

16. Moss, R. H. et al. The next generation of scenarios for climate change research and assessment. Nature 463, 747-756 (2010).

17. Littell, J. S., McKenzie, D., Peterson, D. L. \& Westerling, A. L. Climate and wildfire area burned in western US ecoprovinces 1916-2003. Ecol. Appl. 19, 1003-1021 (2009)

18. Weiss, J. L., Castro, C. L. \& Overpeck, J. T. Distinguishing pronounced droughts in the southwestern United States: Seasonality and effects of warmer temperatures. J. Clim. 22, 5918-5932 (2009).

19. Dominguez, F., Kumar, P., Liang, X-Z. \& Ting, M. Impact of atmospheric moisture storage on precipitation recycling. J. Clim. 19, 1513-1530 (2006)

20. Anderson, B. T., Ruane, A. C., Roads, J. O. \& Kanamitsu, M. Estimating the influence of evaporation and moisture-flux convergence upon seasonal precipitation rates. Part II: An analysis for North America based upon NCEP-DOE Reanalysis II model. J. Hydrometerol. 10, 893-911 (2009).

21. Carle, D. Introduction to Water in California (Univ. California Press, 2004).

22. Vano, J. A., Das, T. \& Lettenmaier, D. P. Hydrologic sensitivities of Colorado River runoff to changes in precipitation and temperature. J. Hydrometerol. 13, 932-949 (2012).

23. Water for Texas 2012 State Water Plan (Texas Water Development Board, 2012); available at http://www.twdb.state.tx.us/waterplanning/swp/.

24. Pierce, D.W. et al. Attribution of declining western US snowpack to human effect. J. Clim. 21, 6425-6444 (2008).

25. Das, T. et al. Structure and detectability of trends in hydrological measures over the western United States. J. Hydrometerol. 10, 871-892 (2009).

26. Das, T., Pierce, D., Cayan, D., Vano, J. \& Lettenmaier, D. The importance of warm season warming to western US streamflow changes. Geophys. Res. Lett. 38, L23403 (2011)

27. Meko, D. M. et al. Medieval drought in the upper Colorado River basin. Geophys. Res. Lett. 34, L10705 (2007).

28. Woodhouse, C. A., Meko, D. M., MacDonald, G. M., Stahle, D. W. \& Cook, E. R. A 1,200 year perspective of 21st Century drought in southwestern North America. Proc. Natl Acad. Sci. USA 50, 21283-21288 (2010).

\section{Acknowledgements}

This work was supported by NOAA awards NA08OAR4320912 and NA10OAR4310137 and NSF award AGS-08-04107. The comments of the wider Global Decadal Hydroclimate Variability and Change $(\mathrm{GloDecH})$ group at Lamont are greatly appreciated.

\section{Author contributions}

R.S., M.T. and B.C. conceived the analyses. R.S. wrote the paper with input from all authors. C.L., H.L., J.N. and N.N. performed analyses on the model data. C.L. and J.N. prepared the figures.

\section{Additional information}

Supplementary information is available in the online version of the paper. Reprints and permissions information is available online at www.nature.com/reprints. Correspondence and requests for materials should be addressed to R.S.

\section{Competing financial interests}

The authors declare no competing financial interests. 